\title{
UN EXTRAÑO NOMBRE DE LA RÓTULA: VOCEUSA
}

\author{
Juan José Barcia Goyanes
}

Universidad de Valencia (España)

\section{RESUMEN}

Entre los sinónimos de la rótula que nos da Berenguer da Carpi en sus Commentaria a la Anatomia de Mondino aparece la palabra "voceusa". El Autor refiere sus intentos de encontrar su significado y la conclusión a que llegó.

\section{SUMMARY}

Among the synonyms of rotula Berengarius Da Carpi gives us in his Commentary to Mondino's work.the word "voceusa".The Author refers his attempts to find its significance and the conclusion he got to.

La investigación del origen y significado de los términos anatómicos, no su etimología que juzgo más allá de mis posibilidades, ha sido para mí una fuente de gratas experiencias pero también, en algún caso, de un vivo sentimiento de ridículo al darme cuenta de que he estado esforzándome en el hallazgo de una solución que tenía delante de las narices, si se me permite esa expresión coloquial. Tal fue la sensación que experimenté al aclarar -así lo creo- el significado del término que encabeza este artículo y que voy a exponer al lector si tiene la paciencia de seguirme.

Pero ante todo, y como contrapunto, voy a exponer brevemente otro enigma y por cierto uno cuyo recuerdo me es especialmente grato en el que el proceso de la solución es justamente el opuesto a aquel del que hoy va a ocuparme.

Se trata de un enigma contra el que se estrelló el bien probado talento investigador de mi maestro el Profesor de Anatomía de Viena Joseph Hyrtl, aunque en realidad el enigma es doble ya que se trata de dos palabras: tharuca y carchametra.

Dice así el maestro vienés, a quien llamo mi Maestro por lo mucho que le debo en el tema de la genealogía de los nombres anatómicos que ha ocupado la parte final de mi vida, en el parágrafo 100 de su obra Das Arabische und Hebraische in der Ana- 


\section{JUAN JOSÉ BARCIA GOYANES}

tomie! "En la nota marginal del capítulo del Canon que trata de la anatomía de los músculos de la cadera (músculos del muslo) encuentro Tharuca y Carchametra con el significado de trocánter mayor y lo mismo en Hugo Senensis, Petrus Antonius Rusticus y entre los sinónimos de Vesalio.

Para explicar estas palabras no sé dónde volverme. No son árabes, ni griegas, ni latinas. El hecho de que en otro lugar del Canon aparezcan las palabras parecidas a Tharuca, Taraca y Altrich, como un tópico para las encías ulceradas (gingiva sanguinea) y que la palabra usada por Paracelso, Trachametra, pueda ser una deformación de Carchametra no aclara nada. La sinonimia del Trocánter que doy a continuación no puede compensarnos de esta pérdida."

Más tarde, en el parágrafo 185 de su Onomatologia Anatomica ${ }^{2}$ volvió sobre el tema.

"Aquí aparecen - decía- Tharuca y Carchametra en las notas marginales de la edición latina de Gerardo de Cremona. Paracelso corrompió Carchametra en Trachametra con lo que cierra el trío de las denominaciones totalmente inexplicables de los trocánteres. No puedo aventurar una hipótesis sobre la genealogía de estas enigmáticas palabras. No son árabes, ni griegas, ni latinas ni romances y pueden tomarse solamente como curiosidades de la construcción de palabras sin sentido."

Como vemos, el tema había interesado al Maestro que declaraba arrojar la toalla en su pelea por la glosa. Y ello fue causa de mi interés en probar fortuna en ella desde la primera vez que leí sus palabras. Pero entonces, en plena vida profesional activa, no disponía ni de tiempo ni de medios para intentarlo. Ya jubilado me encontré con abundancia del primero y con algunos de los segundos.

Y lo primero fue proporcionarme los textos árabes que Hyrtl no manejó —y ello produce verdadero asombro - ya que su fundamental glosa de términos anatómicos árabes y hebreos fue realizada sin apenas conocimiento de estas lenguas y con la ayuda de compañeros de Universidad doctos en ambas.

Y tuve la fortuna de que el primer documento que cayó en mis manos haya sido la edición del Canon de Avicena debida a Bulaq y reproducida en offset por la Muthanna Library de Bagdad ${ }^{3}$. Mi sorpresa fue mayúscula y tambien mi alegría... Uno de los mencionados enigmas aparecía alli claramente revelado. En el libro I del Canon, Fen I, Doctrina V, Suma, 2, capítulo 27 y donde sin duda Avicena habìa escrito "...Y se continúa con la parte más alta de la eminencia mayor la cual se llama trocánter mayor", un copista iletrado había escrito "Y se continúa con la parte mas alta de la eminencia mayor la cual se llama tharuja en relación con el hueso." ملروخا بطير الاعظم (tharuja bi-tair al.çazm).

1 HYRTL, Josep (1879). Das Arabische und Hebräische in der Anatomie. Wien.

2 HYRTL, Josep (1880). Onomatologia Anatomica, Wien.

3 AviCENA, Ibn-sina Abu Ali al-Husain Ibn Abd Allah.al-Qanun fi-I-tibb Nueva edición árabe en offset. Al-Muthanna Library, Baghdad, s.f. 
La explicación es la siguiente. Avicena, después de dar el nombre árabe del trocánter mayor, saidatu al-kubra (prescindo de la grafía árabe para mayor facilidad

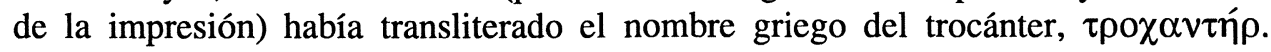
Como en árabe no cabe el fonema $\operatorname{tr}$ y la $o$ no tiene un signo especial sino que se escribe con $g$ wau, lo mismo que la $u$, la transliteración rezaba tarujantir al-âzm (مروخا نطير الاعظم ). El copista, que desconocía tales palabras, pensó que la segunda $a$ de tharujantir era el fin de la palabra que quedaba como tharuja. El resto ntir no tiene ningún sentido, por lo que lo cambió por bi-tair, cosa fácil con sólo cambiar el punto diacrítico de la $n$, situado sobre la letra, por debajo de ella, con lo que se convierte en $b$. El resultado puede significar, "por causa de", "en relación con". Y asimismo cambió el adjetivo "mayor" - âzam — puesto que el adjetivo no tenía allí ningún sentido, por çazm, hueso, quedando la frase tal y como la hemos transcrito más arriba, con lo cual quedaba claro el origen de Tharuja.

El error se debe, pues, a la división de una palabra y su solución a la recomposición de la misma.

Algo semejante ocurrió con carchametra, que pude aclarar gracias al folio 32 del manuscrito Escorial 822. Pero no voy a repetir aquí lo que dije en mi artículo de Medicina Española y que repetí con algunas variantes en mi Onomatología ${ }^{5}$. A ellos remito al lector interesado en el tema. Y paso ya, sin más dilación, al que hoy nos ocupa.

En mi ya citada Onomatología y en la glosa del término patella consulté entre otros documentos los Comentarios de Berenguer Da Carpi a la Anatomía de Mondino ${ }^{6}$, que contienen una rica sinonimia aunque la mayor parte está tomada del Onomastikon de Julius Pollux ${ }^{7}$.

En el folio XXXVI verso y al margen del capítulo De Genu aparecen, de arriba abajo, los siguientes términos:

Addaicon
Rasga
Oculus genu
Mola
Voceusa
Os genuale
Patella
Rotula
Polus

4 BARCIA GoYANES, J. J. (1981). "Dos nombres enigmáticos del trocánter mayor: tharuca y carchametra", Medicina Española, 80, 1981, 1-11.

5 BARCIA GoYANES, J. J. (1983). Onomatologia Anatomica Nova, VI, 311, Valencia.

6 DA CARPI, G. B (1521). Commentaria cum amplissimis additionibus super anatomia Mundini, Bononiae.

7 JUlius POlluX (1536). Pollucis, Julii. Onomastikon, texto griego, Basileae. 
Prescindo de los otros nombres y remito al lector que sobre su glosa esté interesado a mi trabajo sobre los Arabismos en la Fábrica ${ }^{8}$ y voy a fijarme únicamente en Voceusa.

En mi artículo ya mencionado decia: "Otro nombre que da Da Carpi, que no sé de dónde ha podido sacarlo es voceusa, que atribuye a Galeno y remite a U.P III y a AAIV. Pero en este último no se ocupa de nada relacionado con el muslo y debe de tratarse de una errata por II en el que trata de los músculos del muslo. Pero tanto aquí como en De U.P. los nombres que el Pergameno dé a la rótula son los conocidos de

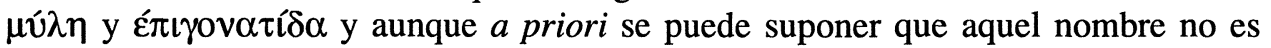
griego no se ve qué término contaminado puede esconderse tras voceusa..."

Más tarde, y en el suplemento de la misma obra, volví a ocuparme de esa palabra, para explicar la cual imaginé una hipótesis de la que ahora prefiero prescindir por lo endeble de su base, una vez que creo haber resuelto el problema. He aquí mi interpretación.

Al pie del capítulo ya citado De Genu se lee: "A G(alenus) III De uti(litate) \& IIII de iuvamentis (De Anatomicis Administrationibus) dicitur voce usa: a quibusdam genuale os vel supergenuale; et cartilaginosum os." Los paréntesis son míos. Y también la separación entre voce y usa(ta), sin la cual leeríamos voceusa.

La traduccion, una vez corregida la errata, queda clara: "En Galeno y en III de Usu Partium y IIII De Anatomicis Administrationibus y con termino usado por algunos (aparece) el nombre de os genuale o supergenuale, hueso cartilaginoso."

Las dudas que pudieran quedarnos por lo defectuoso de la impresión se disipan al ver que esas palabras son transcripción del texto griego de De Usu Partium que reza

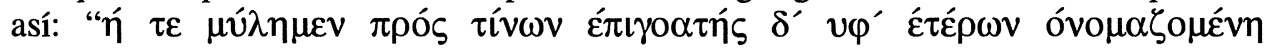

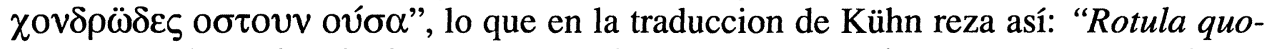
quea nonnulis mola, ab aliis supergenualis vocata, os cartilaginosum existens..."

Podemos preguntarnos por qué ha utilizado Da Carpi el participio usatus en lugar de usitatus, que sería lo correcto. Pero en Du Cange, en su glosario9, encontramos usatus; por otra parte no hay que olvidar que Giacomo Berenguer se llamó Da Carpi por ser de ese pueblo, situado cerca de Módena, y Battisti-Alessio en su Diccionario Etimológico ${ }^{10}$ nos dicen que el participio usato en lugar de usitato fue de uso corriente despues del Dante y la obra del Carpense es de 1521.

Aclarado ya el significado de voceusa vemos que aquí el enigma ha surgido de la union de dos palabras, lo contrario del caso anterior, y que mientras en aquél tuve la fortuna de reconocer a primera vista la "fractura" del trocánter, en éste estuve ciego

8 BARCIA GoYAnES, J. J. (1984). "Los términos árabes en la osteología de Vesalio", Al-Qantara, vol. V, fascs. 1 y $2,293-327$.

9 DU CANGE (1883-1887). Glossarium mediae et infimae latinitatis Unveränderter Nachdruk, Graz 1954, vol. VIII, 386.

10 BATTISTI-ALESSIO (1975). Dizionario Etimologico Italiano, Firenze, vol. V, 3862. 
ante la unión de voce y usata las veces que contemplé el párrafo correspondiente, sin duda sugestionado por la voceusa destacada en el margen.

Pero para consuelo de mi torpeza y estímulo a la benevolencia del lector me permito recordarle que de la misma ceguera fue afectada persona tan calificada en las etimologías de los nombres anatómicos latinos y árabes como Fonahn quien en su obra ${ }^{11}$ y en la página $168, \mathrm{~N}^{\circ} 3624$, señala: Voceusa $=$ Patella, knee-pan, $\sin$ otro comentario.

1 FOREHN, A. (1922) Arabic and Latin Anatomicae Terminology Kristiania. 